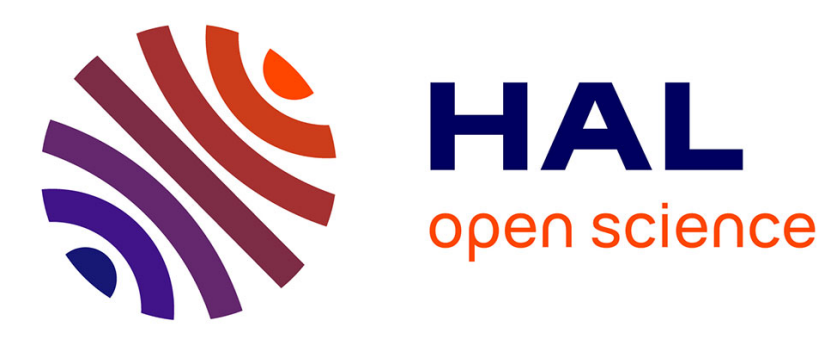

\title{
Functional recombinant human complement C1q with different affinity tags
}

\author{
Isabelle Bally, Sarah Ancelet, Jean-Baptiste Reiser, Véronique Rossi, \\ Christine Gaboriaud, Nicole M. Thielens
}

\section{> To cite this version:}

Isabelle Bally, Sarah Ancelet, Jean-Baptiste Reiser, Véronique Rossi, Christine Gaboriaud, et al.. Functional recombinant human complement C1q with different affinity tags. Journal of Immunological Methods, 2021, 492, pp.113001. 10.1016/j.jim.2021.113001 . hal-03152614

\section{HAL Id: hal-03152614 https://hal.univ-grenoble-alpes.fr/hal-03152614}

Submitted on 25 Feb 2021

HAL is a multi-disciplinary open access archive for the deposit and dissemination of scientific research documents, whether they are published or not. The documents may come from teaching and research institutions in France or abroad, or from public or private research centers.
L'archive ouverte pluridisciplinaire HAL, est destinée au dépôt et à la diffusion de documents scientifiques de niveau recherche, publiés ou non, émanant des établissements d'enseignement et de recherche français ou étrangers, des laboratoires publics ou privés. 


\section{Journal Pre-proof}

Functional recombinant human complement $\mathrm{Clq}$ with different affinity tags

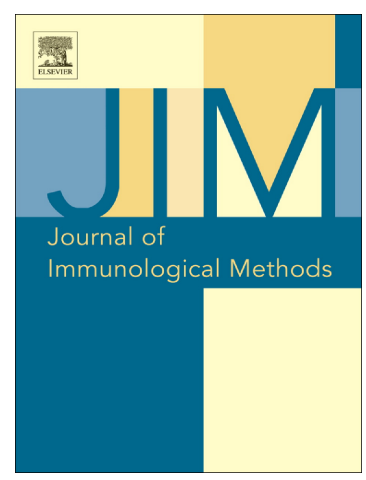

Isabelle Bally, Sarah Ancelet, Jean-Baptiste Reiser, Véronique Rossi, Christine Gaboriaud, Nicole M. Thielens

PII: $\quad$ S0022-1759(21)00046-6

DOI: $\quad$ https://doi.org/10.1016/j.jim.2021.113001

Reference: $\quad$ JIM 113001

To appear in: $\quad$ Journal of Immunological Methods

Received date: $\quad 5$ January 2021

Revised date: $\quad 14$ February 2021

Accepted date: $\quad 16$ February 2021

Please cite this article as: I. Bally, S. Ancelet, J.-B. Reiser, et al., Functional recombinant human complement C1q with different affinity tags, Journal of Immunological Methods (2019), https://doi.org/10.1016/j.jim.2021.113001

This is a PDF file of an article that has undergone enhancements after acceptance, such as the addition of a cover page and metadata, and formatting for readability, but it is not yet the definitive version of record. This version will undergo additional copyediting, typesetting and review before it is published in its final form, but we are providing this version to give early visibility of the article. Please note that, during the production process, errors may be discovered which could affect the content, and all legal disclaimers that apply to the journal pertain.

(C) 2019 Published by Elsevier. 


\section{Functional recombinant human complement C1q with different affinity tags}

Isabelle Bally ${ }^{1}$, Sarah Ancelet ${ }^{1}$, Jean-Baptiste Reiser ${ }^{1}$, Véronique Rossi ${ }^{1}$, Christine Gaboriaud $^{1}$ and Nicole M. Thielens ${ }^{1}$

${ }^{1}$ Univ. Grenoble Alpes, CEA, CNRS, IBS, F-38000 Grenoble, France.

\section{Corresponding Author}

Nicole M. Thielens

Institut de Biologie Structurale

CAMPUS EPN

71, avenue des Martyrs

CS 10090

38044 Grenoble CEDEX 9

Tel. +33457428705

Fax. +33476501890

Email: nicole.thielens@ibs.fr
Abbreviations
CLR
collagen-lise : agion
GR
globulà re ren. $_{e}$.
NHS
normal hus an serum
SPR
surface plasmon resonance 


\begin{abstract}
Complement $\mathrm{C} 1 \mathrm{q}$ is a multifunctional protein able to sense pathogens and immune molecules such as immunoglobulins and pentraxins, and to trigger the classical complement pathway through activation of its two associated proteases, $\mathrm{C} 1 \mathrm{r}$ and $\mathrm{C} 1 \mathrm{~s}$. C1q is a multimeric protein composed of three homologous yet distinct polypeptide chains A, B, and C, each composed of an $\mathrm{N}$-terminal collagen-like sequence and a C-terminal globular gC1q module, that assemble into six heterotrimeric (A-B-C) subunits. This hexameric structure exhibits the characteristic shape of a bouquet of flowers, comprising six collagen-like triple helices, each terminating in a trimeric C-terminal globular head. We have produced previously functional 1 combinant full-length $\mathrm{C} 1 \mathrm{q}$ in stably transfected HEK 293-F cells, with a FLAG tag inserted th th e C-terminal end of C1qC chain. We report here the generation of additional recombira. $\mathrm{t} C \mathrm{q}$ proteins, with a FLAG tag

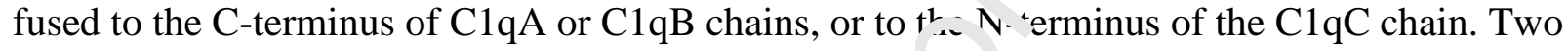
other variants harboring a Myc or a 6-His tag at the C-ten inal end of C1qC were also produced. We show that all C1q variants, except for the His- ar,g d protein, can be produced at comparable yields and are able to bind with similar affir.. as ? either $\operatorname{IgM}$, a ligand of the globular regions, or to the $\mathrm{C}_{1} \mathrm{r}_{2}-\mathrm{C} 1 \mathrm{~s}_{2}$ tetramer, and to trigger ${ }_{c}-M$-mediated serum complement activation. These new recombinant $\mathrm{C} 1 \mathrm{q}$ variants provide ar' ditional tools to investigate the multiple functions of C1q.
\end{abstract}

Key Words: Complement, C1q, recombinant protein, affinity tag, interaction properties 


\section{Introduction}

The C1q protein is part of the initiating complex of the classical complement pathway (called $\mathrm{C1}$ ), an important actor of humoral innate immunity in mammals. Besides C1q, C1 comprises two homologous serine proteases, $\mathrm{C} 1 \mathrm{r}$ and $\mathrm{C} 1 \mathrm{~s}$ that are associated in $\mathrm{C} 1 \mathrm{r}_{2}-\mathrm{C} 1 \mathrm{~s}_{2}$ tetramer. Binding of $\mathrm{C} 1 \mathrm{q}$ to danger or damage signals, including antigen-antibody complexes and factors present at the surface of pathogens or infected cells, triggers auto-activation of C1r, which then activates C1s and initiates the complement proteolytic cascade (Reid, 2018). Complement activation leads to target opsonization for enhanced phagocytosis, to the development of an inflammatory response and ultimately triggers the lytic pathway for 'estruction of complementsensitive pathogens (Merle et al., 2015; Ricklin et al., 2010). In ‘ tdit on, C1q recognizes altered self-elements including apoptotic cells and contributes to the ${ }_{-1}^{*}$ sat 2 elimination and maintenance of host tissue homeostasis (Lu et al., 2008; Ricklin et al, $2 n_{1} ?$ ). C1q is also involved in several non-canonical functions including modulation of immunc ells, coagulation, development, and in the pathogenesis of numerous diseases, among wh ct. central nervous system disorders, pregnancy complications and cancer (Kouse. 't a' '. 2015; Nayak et al., 2010; Thielens et al., 2017). These functions arise from the bindı, versatility of C1q for an amazing variety of soluble and cell surface ligands, a featurc related to the complexity of its structure.

$\mathrm{C} 1 \mathrm{q}$ is a high molecular weight (abou $461, \mathrm{kDa})$ multimeric protein assembled from 18 polypeptide chains of three types: $\mathrm{C} 1_{4} \mathrm{~A}, 6 \mathrm{C} 1 \mathrm{qB}$ and $6 \mathrm{C} 1 \mathrm{qC}$ chains, each containing a collagen-like N-terminal regic: aı t a globular gC1q C-terminal domain. The A and B chains are linked by a disulfide bond $n^{n}$ " 2 non-covalently associated with a $\mathrm{C}$ chain to form a heterotrimeric collagen ${ }^{2} i_{k}$ : ${ }^{2}$ elix terminating in a trimeric globular region. In addition, a disulfide bond between ${ }^{\circ} \mathrm{C}$ chains results in a basic subunit composed of two heterotrimers and three subunits compose the C1q molecule with an overall characteristic shape of a bouquet of flowers (Fig. 1A). From a functional point of view, C1q contains two regions, the globular regions responsible for $\mathrm{Clq}$ binding to its targets, including immunoglobulins, and the collagenlike regions responsible for association with its cognate $\mathrm{C} 1 \mathrm{r}$ and $\mathrm{C} 1 \mathrm{~s}$ proteases and most $\mathrm{C} 1 \mathrm{q}$ cell receptors (Reid, 2018).

This complexity of the $\mathrm{C} 1 \mathrm{q}$ molecule accounts for the fact that its expression in a recombinant form could be achieved only a few years ago. We were able to produce a full-length functional recombinant C1q molecule using HEK 293-F cells stably transfected with plasmids encoding 
each of its three chains (Bally et al., 2013). The generation of different recombinant C1q proteins with point mutations in the collagen-like regions or in the globular regions allowed us to identify important residues for $\mathrm{C} 1 \mathrm{q}$ interaction with its associated proteases or for binding to immunoglobulins and pentraxins, respectively (Bally et al., 2013, 2019b; Espericueta et al., 2020). All reported C1q mutants were generated based on a recombinant protein with a FLAG tag inserted at the $\mathrm{C}$-terminal end of $\mathrm{C} 1 \mathrm{qC}$ chain. With a view to generate additional recombinant $\mathrm{C} 1 \mathrm{q}$ protein tools, we investigated the possibility to produce recombinant $\mathrm{C} 1 \mathrm{q}$ either with a different tag (Myc or 6-histidine) located at the C-terminus of C1gC, or with a FLAG tag at different locations ( $\mathrm{N}$-terminus of $\mathrm{C} 1 \mathrm{qC}, \mathrm{C}$-terminus of $\mathrm{ClqA}$ or $\mathrm{C} 1 \mathrm{~B})$. The ability of the purified newly produced variants to interact with $\operatorname{IgM}$, a ligand t and with the $\mathrm{C}_{1} \mathrm{r}_{2}-\mathrm{C} 1 \mathrm{~s}_{2}$ tetramer, associated to the collagen-li e s' alks was investigated, as well as their serum complement activating capacity. The func $\therefore \eta_{a^{\prime}}$ properties of these variants were compared with those of the initially produced recombina . $^{\prime} 1 \mathrm{q}$ with a FLAG tag at the Cterminal end of the $\mathrm{C}$ chain.

\section{Material and Methods}

\subsection{Proteins and Reagents}

Human IgM and BSA were from Sigı.n. Iie molar concentration of IgM was estimated using a Mr of 900,000 and $A_{1 \%, 1 c m}$ at 28c, $1 \mathrm{~m}$ of 11.8. L-ascorbic acid and L-ascorbic acid 2-phosphate were from Sigma. Oligonuclec tia - were from Eurogentec and restriction and modification enzymes from New England $\mathrm{L}:$ : iabs.

\subsection{Expression Vectors}

The pcDNA3.1 plasmids coding for the individual $\mathrm{C} 1 \mathrm{qA}, \mathrm{C} 1 \mathrm{qB}$ and $\mathrm{C} 1 \mathrm{qC}$ chains and containing neomycin-, hygromycin-, and zeocin-resistance genes, respectively, have been described previously (Bally et al., 2013). The pcDNA3.1_C1qA and pcDNA3.1_C1qB plasmids were used as templates to generate expression vectors for $\mathrm{C} 1 \mathrm{qA}$ and $\mathrm{C} 1 \mathrm{qB}$ chain with a $\mathrm{C}$-terminal FLAG epitope (DYKDDDDK) (pcDNA3.1_C1qA-FLAG and pcDNA3.1_C1qB_FLAG) by sitedirected mutagenesis (Quick Change XL site-directed mutagenesis kit; Agilent Technologies). The vectors for expression of $\mathrm{C} 1 \mathrm{qC}$ chain with an N-terminal FLAG epitope (pcDNA3.1_FLAG-C1qC), a C-terminal Myc epitope (EQKLISEEDL) (pcDNA3.1_C1qC- 
Myc), or a C-terminal 6-histidine tag (pcDNA3.1_C1qC-His) were generated in the same way, using the pcDNA3.1_C1qC plasmid as a template. The mutagenic oligonucleotides used are provided in Table S1. All constructs were verified by DNA sequencing (GATC Biotech).

\subsection{Stably Transfected Cell Lines}

Stable FreeStyle 293-F cell lines producing the individual B and C, or A and C chains of C1q were generated as described previously for the stable transfectants expressing the A and B chains of C1q (Bally et al., 2013). Cells producing the C1qB and C1qC chains, grown in FreeStyle 293 medium supplemented with $100 \mu \mathrm{g} / \mathrm{ml}$ hygromycin (Thermo Fishe $i$, and $10 \mu \mathrm{g} / \mathrm{ml}$ zeocin (Thermo Fisher), were transfected with the C1qA-FLAG-contail ing llasmid, and stable transfectants producing the three $\mathrm{Clq}$ chains were obtained f, llov ing additional selection with $400 \mu \mathrm{g} / \mathrm{ml} \mathrm{G} 418$ (Thermo Fisher). In the same way, stab', tra ?sfectants producing C1qA and $\mathrm{C} 1 \mathrm{qC}$ chains were transfected with the C1qB-FLAG-con $:$ iling plasmid, and stably transfected cells producing the three $\mathrm{Clq}$ chains were obtaine if $\mathrm{Jl}$ 'owing additional selection with 100 $\mu \mathrm{g} / \mathrm{ml}$ hygromycin. Stably transfected cells ${ }^{\prime} \mathrm{du}_{\mathrm{u}}$ ing $\mathrm{C} 1 \mathrm{qA}$ and $\mathrm{C} 1 \mathrm{qB}$ chains were transfected with the pcDNA3.1_FLAG-C1qC, pcDNA. _C1qC-myc or pcDNA3.1_C1qC-His plasmids and stable transfectants expressing the the chains obtained after selection with $10 \mu \mathrm{g} / \mathrm{ml}$ zeocin. Cells producing C1q with a F $/ \mathbf{A}$ - - ag at the C-terminal end of the C-chain (rC1q_CFLAG) have been described previ, usly (Bally et al., 2013).

\subsection{Production and purifiratic.' f Clq variants}

The cells expressing ei $\cdot h_{\text {_ }}$ :ne six different C1q variants, rC1q_A-FLAG, rC1q_B-FLAG, rC1q_C-FLAG, rC1q_F _.G-C, rC1q_C-myc or rC1q_C-His, were expanded in the Freestyle 293 expression medium containing the three selection antibiotics and supplemented with $250 \mu \mathrm{M}$ L-ascorbic acid and $450 \mu \mathrm{M}$ L-ascorbic acid 2-phosphate (Koch et al., 2006). The culture medium was harvested and replaced every $72 \mathrm{~h}$ up to three times. All recombinant $\mathrm{C} 1 \mathrm{q}$ variants were purified from the culture supernatants using a first step of adsorption on insoluble IgGovalbumin aggregates (Arlaud et al., 1979). The extracts containing rC1q with a FLAG or Myc tag were dialyzed against $50 \mathrm{mM}$ Tris- $\mathrm{HCl}$ and $150 \mathrm{mM} \mathrm{NaCl}(\mathrm{pH}$ 7.4). C1q variants with a FLAG-tag were further purified by chromatography on an anti-FLAG M2 affinity column (Sigma-Aldrich) as described previously (Bally et al., 2013). The rC1q_C-Myc extract was 
applied to a $2 \mathrm{ml}$ anti-c-Myc agarose affinity column (Pierce) equilibrated in the dialysis buffer. After washing with $20 \mathrm{ml}$ of the equilibration buffer, the bound material was eluted twice with 2 $\mathrm{ml}$ of a $1 \mathrm{mg} / \mathrm{ml}$ solution of c-Myc peptide (Sigma-Aldrich) in the same buffer. The eluted fractions were dialyzed against $50 \mathrm{mM}$ Tris- $\mathrm{HCl}$ and $150 \mathrm{mM} \mathrm{NaCl}(\mathrm{pH} \mathrm{7.4)}$ and concentrated to 0.3-0.4 mg/ml. The rC1q_C-His extract was dialyzed against PBS containing $10 \mathrm{mM}$ imidazole and applied to a $1.5 \mathrm{ml}$ HIS-Select HF Nickel Affinity column (Sigma) equilibrated in the dialysis buffer. After washing with $20 \mathrm{ml}$ of the equilibration buffer, the bound material was eluted in PBS containing $300 \mathrm{mM}$ imidazole. The eluted fractions were dialyzed against $50 \mathrm{mM}$ Tris- $\mathrm{HCl}$ and $150 \mathrm{mM} \mathrm{NaCl}(\mathrm{pH} 7.4)$ and concentrated to $0.3-0.41 \mathrm{Ic}_{c}^{-1} \mathrm{ml}$. The concentration of purified $\mathrm{rC1q}$ was estimated using an absorption coefficient $\left(\mathrm{A}_{1 \%} \quad 1 \mathrm{cr}\right)$ at $280 \mathrm{~nm}$ of 6.8 and a $\mathrm{Mr}$ value of 460,000. Recombinant rC1q variants were analyzed vy s sdium dodecyl sulfatepolyacrylamide gel electrophoresis (SDS-PAGE) under $\ldots$ n-1 ${ }^{2}$ ducing and reducing conditions using Tris- $\mathrm{HCl}$ gels containing $14 \%$ polyacrylamide, ana ulored using Instant Blue (Expedeon).

\subsection{Production of the recombinant proenzyr _ C $C_{i}{ }_{2}-C_{1} s_{2}$ tetramer}

The recombinant proenzyme $\mathrm{C}_{1} \mathrm{r}_{2}-\mathrm{C} 1 \mathrm{~s}_{2}$ tetra $\mathrm{ler}$ was obtained by co-transfection with plasmids encoding $\mathrm{C} 1 \mathrm{r}$ and $\mathrm{C} 1 \mathrm{~s}$ serine proteases, $\mathrm{c}$. ch stabilized in a zymogen form by mutation of the active site serine residues $637(\mathrm{C} 1 \mathrm{r})$ a.r. $6.7(\mathrm{C} 1 \mathrm{~s})$ to alanine (mature proteins numbering). The tetramer was produced in the Frec.: "tyle 293 Expression System (Thermo Fisher), using a pcDNA3.1/Zeo(+) plasmid en، na. g human C1r with the Ser637Ala mutation (Bally et al., 2019b) and a pcDNA3.1/Nan : plasmid encoding human C1s with the Ser617Ala mutation. The latter was generatt. ${ }^{b} \mathrm{~b}$; ice-directed mutagenesis using the pcDNA3.1/Neo(+) plasmid encoding human C1s $w^{* t}$ a C-terminal FLAG tag (Bally et al., 2019a) as a template and the mutagenic primers described in Table S1. Generation of stably co-transfected 293-F cells and purification of the recombinant proenzyme tetramer from the culture supernatant by anti-FLAG affinity chromatography were performed as described in (Bally et al., 2013). The molar concentration of the tetramer was estimated using a Mr value of 344,500 and an absorption coefficient $\left(\mathrm{A}_{1 \%, 1 \mathrm{~cm}}\right)$ at $280 \mathrm{~nm}$ of 13.45 .

\subsection{SPR analyses and data evaluation}


Analyses were performed at $25^{\circ} \mathrm{C}$ using a Biacore T200 instrument (Cytiva). The C1q variants and BSA, diluted at $50 \mu \mathrm{g} / \mathrm{ml}$ in $10 \mathrm{mM}$ sodium acetate $\mathrm{pH} 4.5$ and $25 \mu \mathrm{g} / \mathrm{ml}$ in $10 \mathrm{mM}$ sodium acetate $\mathrm{pH} 4$, respectively, were immobilized on CM5 sensor chips (Cytiva) using the amine coupling chemistry in $10 \mathrm{mM}$ Hepes, $150 \mathrm{mM} \mathrm{NaCl}, 3 \mathrm{mM}$ EDTA, $0.05 \%$ surfactant P20, pH 7.4. Binding was measured at a flow rate of $20 \mu \mathrm{l} / \mathrm{min}$ in $50 \mathrm{mM}$ Tris- $\mathrm{HCl}, 150 \mathrm{mM} \mathrm{NaCl}, 2 \mathrm{mM}$ $\mathrm{CaCl}_{2}, 0.05 \%$ surfactant $\mathrm{P} 20, \mathrm{pH}$ 7.4. The specific binding signal was obtained by subtracting the signal over the BSA reference surface. The surfaces were regenerated by $10 \mu 1$ injections of $1 \mathrm{M}$ $\mathrm{NaCl}, 10 \mathrm{mM}$ EDTA, pH 7.4. Kinetic data were analyzed by global fitting to a 1:1 Langmuir binding model for six concentrations simultaneously, using the Biau re T200 evaluation 2.0 software (Cytiva). Buffer blanks were subtracted from the data $s$ ts $v$;ed for kinetic analyses. The apparent equilibrium dissociation constants $\left(K_{\mathrm{D}}\right)$ were ra' $^{\prime}$ cul ted from the ratio of the

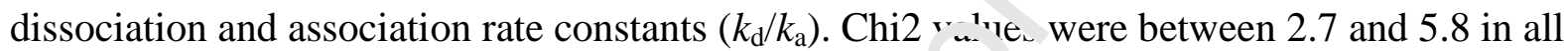
cases.

\subsection{Classical complement pathway activatic . TS, 'vs}

Microtiter plates (Maxisorp Nunc) were coa d with $\operatorname{IgM}(2 \mu \mathrm{g} / \mathrm{ml})$ in $35 \mathrm{mM} \mathrm{NaHCO}_{3}, 15 \mathrm{mM}$ $\mathrm{Na}_{2} \mathrm{CO}_{3}$, pH 9.6 overnight at $4{ }^{\circ} \mathrm{C}$. Wells were saturated for $1 \mathrm{~h}$ at $37{ }^{\circ} \mathrm{C}$ with $2 \% \mathrm{BSA}(\mathrm{w} / \mathrm{v}$ ) in PBS and washed with PBS containing . .0;\% Tween 20 (PBS-T). C1q-depleted serum (CompTech), diluted 1:25 in $5 \mathrm{mi}$ ' $\mathrm{Na}$ veronal, $145 \mathrm{mM} \mathrm{NaCl}, 5 \mathrm{mM} \mathrm{CaCl} 2,1.5 \mathrm{mM} \mathrm{MgCl}$, $\mathrm{pH} 7.5$ and reconstituted with . he . ${ }^{\circ}$ combinant $\mathrm{C} 1 \mathrm{q}$ variants $(4 \mu \mathrm{g} / \mathrm{ml})$, was added to the wells and incubated for $1 \mathrm{~h}$ at $37^{\circ} \mathrm{C}$. The wells were washed with $5 \mathrm{mM}$ Na veronal, $145 \mathrm{mM} \mathrm{NaCl}, 5$ mM EDTA, pH 7.5 be $r$ re dition of a rabbit anti-C4 polyclonal antibody (diluted 1:1,000 in PBS-T with $0.2 \%$ BSA $(* / v)$ ) (Siemens Healthcare Diagnostics) and incubation for $1 \mathrm{~h}$ at $37{ }^{\circ} \mathrm{C}$. After washing with PBS-T and incubation with a peroxidase-conjugated goat anti-rabbit polyclonal antibody (diluted 1:20,000 in PBS-T with $0.2 \%$ BSA (w/v)) (Jackson ImmunoResearch) for $1 \mathrm{~h}$ at $37^{\circ} \mathrm{C}$, plates were washed with PBS-T and developed with 3,3',5,5'tetramethylbenzidine (Tebu). The reaction was stopped with $1 \mathrm{~N} \mathrm{H}_{2} \mathrm{SO}_{4}$ and absorbance was read at $450 \mathrm{~nm}$. Each assay was performed in duplicate. Normal human serum (NHS) was obtained from the Etablissement Français du Sang Rhône-Alpes (agreement number 14-1940 regarding its use in research) and used as a positive control. 


\section{Results}

\subsection{Production and biochemical characterization of the Clq variants}

The original recombinant $\mathrm{C} 1 \mathrm{q}$ (C1q_C-FLAG) and five new variants have been produced, harboring fusion tags differing in nature (FLAG, Myc or His) and location (C-terminal end of C1qA, C1qB or C1qC, or N-terminal end of C1qC), named herein C1q_A-FLAG, C1q_BFLAG, C1q_FLAG-C, C1q_C-Myc and C1q_C-His. The C1q variants were produced in 293-F cells stably transfected with the three C1q chains (two untagged and one tagged chains). The recombinant proteins were purified from the cell culture supernatants based on C1q affinity for insoluble IgG-ovalbumin aggregates, as described previously for C1: C-FLAG (Bally et al., 2013). Further purification was achieved based on the nature of ine $f$ sion tag, using a resin functionalized with anti-FLAG or anti-Myc antibodies, or vi $\mathrm{h}$ in mobilized nickel ions, aiming at elimination of the contaminating $\operatorname{IgG}$ molecules arisir ${ }_{0}{ }^{f_{\mathrm{r}} . \eta}$ the preceding step. The amount of purified concentrated protein recovered from 11 of c'lı. .e supernatant varied from $0.35 \mathrm{mg}$ (variants with the FLAG-tag at the C-terminus of $1 \wedge, \mathrm{C} 1 \mathrm{qB}$ or $\mathrm{C} 1 \mathrm{qC}$ chain), to 0.4 and 0.55 $\mathrm{mg}$ for the $\mathrm{C}$-ter Myc- and $\mathrm{N}$-ter FLAG-tag ${ }_{2}{ }^{-1} \mathrm{C}^{1} \mathrm{qC}$ variants, respectively. A very low amount of protein was recovered in the case of the ant harboring a C-terminal His-tagged $\mathrm{C} 1 \mathrm{qC}$ chain (less than $4 \mu \mathrm{g}$ from $400 \mathrm{ml}$ culturc supernatant) which proved in addition to be still contaminated with IgG (Fig. 1B, C). L S S I AGE analysis of the five other variants yielded typical C1q band patterns, with ch racturistic A-B and C-C dimers under non-reducing conditions (Fig. 1A, B) and ths the A, B and C chains under reducing conditions (Fig.1A, C), with small differences betwoe. t'.le variants accounting for the presence of the tags on the

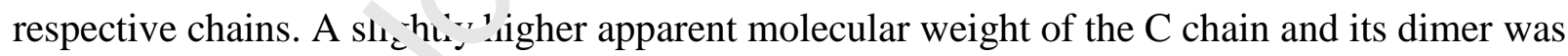
observed for the three vants with a tagged C-chain, independently of the tag nature (FLAG or Myc) or location. In the same way, the apparent molecular weights of the FLAG-tagged A and B chains were slightly higher than those of their non-tagged counterparts, a difference only visible under reducing conditions (Fig. 1C) since the A-B dimers migrated similarly (Fig. 1B). It should be noted that the untagged A chain and FLAG-tagged B chain could not be separated under reducing conditions (Fig.1C). Indeed, addition of a tag to the B chain induces a slight increase in its apparent molecular weight, resulting in migration at the same level as untagged A chain and merging of both bands. SDS-PAGE and Western blot analysis of the culture supernatant corresponding to C1q_C-His, using a polyclonal anti-Clq antibody, revealed the presence of the 
three chains under reducing conditions, but of only very low amounts of A-B and of virtually no C-C dimers under non-reducing conditions (not shown). This observation strongly suggested that most of this recombinant variant was not correctly assembled, and did not interact with immune complexes in the first purification step. The functional characterization of the C1q variants was next performed with all samples, except for C1q_C-His.

\subsection{Interaction properties of the Clq variants with IgM and C1r and C1s proteases}

The functionality of the C1q variants was first investigated by SPR analysis of their interaction with two emblematic physiological ligands of C1q globular and coin oen-like regions, IgM and the $\mathrm{C}_{1} \mathrm{r}_{2}-\mathrm{C} 1 \mathrm{~s}_{2}$ tetramer, respectively. IgM bound to immobilized $\mathrm{C} 1 \mathrm{c} \_\mathrm{C}-\mathrm{FLAG}$ variant, in accordance with our previous data (Bally et al., 2019b) (Fig. 'A). and also to the four other variants (Fig. 2B-E). Kinetic analyses of the interactions $\mathrm{gl}_{\mathrm{c}}^{\prime} \mathrm{ed}$ association rate constants $\left(k_{\mathrm{a}}\right)$ in the same range $\left(1.10-1.78 \times 10^{6} \mathrm{M}^{-1} \mathrm{~s}^{-1}\right)$ and similar dissc ation rate constants $\left(k_{\mathrm{d}}\right)(1.75-1.85 \mathrm{x}$ $10^{-3} \mathrm{~s}^{-1}$ ) for all $\mathrm{Clq}$ variants (Table 1 ). The deduce $\mathrm{d}$; $\mathrm{p}$ ) arent $K_{\mathrm{D}}$ values were in the $\mathrm{nM}$ range (1.0 - $1.6 \mathrm{nM})$, reflecting a comparable high ${ }_{\sim}^{c} f_{11}: t_{y}$ of the five C1q variants for IgM. In the same way, the $\mathrm{C}_{1} \mathrm{r}_{2}-\mathrm{C} 1 \mathrm{~s}_{2}$ tetramer interacted with : nmobilized C1q_C-FLAG variant (Fig. 2F), as reported in our previous studies (Bally eı ^l., 2019b, 2013) and with the four other C1q variants (Fig. 2G-J). Kinetic analyses yielded is, 0 ration and dissociation rate constants in the same range $\left(k_{\mathrm{a}}=5.55-9.40 \times 10^{5} \mathrm{M}^{-1} \mathrm{~s}^{-1}\right.$ and $\left.\kappa_{\mathrm{d}}=2.90-3.66 \times 10^{-3} \mathrm{~s}^{-1}\right)$, resulting in comparable apparent dissociation constants $\left(K_{\mathrm{D}}=3.7-2 \mathrm{nM}\right)$ (Table 1). These data indicated that the presence of the tags had no significant imrnat $r$ the functionality of both globular and collagen-like regions within the recombinanı $\tau_{1:}$.

\subsection{IgM-dependent serum complement activation by the Clq variants}

The capacity of the $\mathrm{C} 1 \mathrm{q}$ variants to trigger activation of the classical complement pathway was next analyzed in a $\mathrm{C} 4 \mathrm{~b}$ deposition assay, using wells coated with $\operatorname{IgM}$ and C1q-depleted human serum as a source of complement components ( $\mathrm{C} 1 \mathrm{r} / \mathrm{C} 1$ s proteases and $\mathrm{C} 4)$. As expected, the five C1q variants yielded amounts of deposited C4b comparable to those obtained with NHS whereas no significant signal was observed with C1q-depleted serum (Fig. 3). These results confirmed the functionality of the C1q variants, in accordance with the SPR interaction analyses. 


\section{Discussion}

The only recombinant full-length $\mathrm{C} 1 \mathrm{q}$ protein currently available has been engineered with a FLAG-tag fused to C1qC chain (rC1q_C-FLAG) and could be used since as a template for the generation of mutants to map ligand binding sites in the collagen-like and globular regions (Bally et al., 2019b, 2013). Our initial tag choice had been motivated by our unpublished observations suggesting that the formation of the disulfide-linked C-C dimer was a limiting factor in the assembly of the full-length molecule.

We show here that the location of the tag does not appear as a limiting factor for production of a functional recombinant $\mathrm{C} 1 \mathrm{q}$ protein. Indeed, fusion of the FLAG tay tt the C-terminal end of $\mathrm{C} 1 \mathrm{qA}$ or $\mathrm{C} 1 \mathrm{qB}$ chain allowed production of recombinant $\mathrm{C} 1 \mathrm{q} \mathrm{w}_{\mathrm{t}}$ th $\mathrm{e}$.pected binding properties for IgM, a major ligand of its globular regions. This lack of $i_{i}$ terf rence can likely be explained by the position of the $\mathrm{C}$-terminal tags in the 3-D structur at he globular regions of C1q. Indeed, as revealed by the X-ray crystal structure of the globular . sion of C1q (Gaboriaud et al., 2003; Moreau et al., 2016), the $\mathrm{N}$ - and C-termini of the $\mathrm{t}$ r $\mathrm{e}$ gClq modules emerge at the base of the trimer. Thus, addition of a FLAG-tag at $\mathrm{C} 1 r_{\wedge}{ }^{*} \mathcal{C}^{1} \mathrm{qB}$ or $\mathrm{C} 1 \mathrm{qC}$ chain results in the location of the tag in a common area at the base of the GR, rose to the junction with the collagen-like region of C1q (Fig. 4). The fact that the interaction , roperties with the associated proteases are intact confirms the correct assembly of the $0^{\prime} \mathrm{l}_{5} \mathrm{en}$ stalks of the $\mathrm{C} 1 \mathrm{q}$ variants. Interestingly enough, fusion of the tag with the $\mathrm{N}$-termi. ' is o $\mathrm{C} 1 \mathrm{qC}$ had also no detectable impact on $\mathrm{C} 1 \mathrm{q}$ ability to interact either with $\mathrm{IgM}$ or wit- the $\mathrm{C} 1 \mathrm{r} / \mathrm{C} 1 \mathrm{~s}$ proteases. Although the corresponding variants harboring the FLAG tag $\mathrm{a}^{\text {t the }} \mathrm{N}^{\mathrm{T}}$-terminus of $\mathrm{C} 1 \mathrm{qA}$ or $\mathrm{C} 1 \mathrm{qB}$ were not produced in the present study, it may be assum 1 in: they would be functional since the $\mathrm{N}$-terminal extremities of the three chains are also in '"se proximity (Fig. 4). Indeed, a cysteine residue engaged in a disulfide bond (A-B and $\mathrm{C}-\mathrm{C}$ ) is present at the fourth position of each mature $\mathrm{C} 1 \mathrm{q}$ chain. In addition, the present study points out that the nature of the tag rather than its position has likely a bigger impact on recombinant $\mathrm{C} 1 \mathrm{q}$ production. Indeed, fusion of $\mathrm{C} 1 \mathrm{qC}$ chain to a $\mathrm{C}$ terminal His tag strongly diminished the recovery of correctly folded material and yielded contaminated purified material, precluding functional characterization of this $\mathrm{C} 1 \mathrm{q}$ variant. In contrast, insertion of a C-terminal Myc tag yielded a C1q molecule with functional properties undistinguishable from its FLAG-tagged counterpart. The reason of this differential behavior of the recombinant proteins might result from the negatively charged nature of either FLAG 
(DYKDDDDK) or Myc (EQKLISEEDL) tag, by comparison with 6-His tag, possibly influencing the tag orientation through electrostatic interactions with neighboring protein residues. The low recovery of the His-tagged variant could also be related to the presence in the GR of a solvent exposed calcium ion, likely contributing to the stability of the GR (Gaboriaud et al., 2003) and possibly removed by the presence of imidazole and nickel ions in the metal chelate chromatography step (Kutyshenko et al., 2019). The lack of interference with C1q variants interaction with IgM can be explained by the tag location at the junction of the GR and CLR, an area not involved in the interaction with immune ligands such as immunoglobulins and pentraxins. Both interactions were shown previously to involve preı "entially B chain Arg residues that line the side of the $\mathrm{gClq}$ heterotrimer, with a minos nar icipation of a Tyr residue located at the apex of gC1q trimer (Bally et al., 2019b; Gadic 'a e al., 2008; Roumenina et al., 2006; Zlatarova et al., 2006). (Fig. 4)

In conclusion, we have produced novel functional $\mathrm{C} 1 \mathrm{q} \mathrm{va}_{\mathbf{a}}$ ants with affinity tags differing in the tag nature and location, which open new possibilit es for future studies where use of a Myc tag rather than a FLAG tag would be desirable, $\therefore \epsilon^{-}$ample in pull-down experiments. These variants proved to be functional regarding th- ir capacity to interact with two canonical C1q ligands involving either the globular or c. llagen-like regions. However, a possible interference of the $\mathrm{C}$-terminal tags cannot be exch $d \cdot d$ in case of a ligand binding site located at the junction of the CLR and GR, as proposed $r$ evicusly for fibronectin (Reid and Edmondson, 1984). This possible issue could be overcc ne $\mathrm{y}$ using a tag fused to the $\mathrm{N}$-terminus part of $\mathrm{C} 1 \mathrm{q}$ chains. These recombinant full-len $\approx$ th $m$ slecules represent additional tools to study the functional versatility of the $\mathrm{C} 1 \mathrm{q} \mathrm{p}_{\mathrm{n}} \mathrm{ntc}: \mathrm{n}$, together with the recombinant single chain globular regions (Moreau et al., 2016) ar. ${ }^{-1}$.he recently produced recombinant CLRs obtained by substitution of C1q GR by the nc2 domain of type IX collagen (Fouët et al., 2020).

\section{Declaration of Competing Interest}

IB and NMT are co-inventors of a patent describing a method for preparing C1q recombinant protein.

\section{Acknowledgements}


This work used the SPR facility at the Grenoble Instruct-ERIC Center (ISBG; UMS 3518 CNRS CEA-UGA-EMBL) with support from the French Infrastructure for Integrated Structural Biology (FRISBI; ANR-10-INSB-05-02) and GRAL, a project of the University Grenoble Alpes graduate school (Ecoles Universitaires de Recherche) CBH-EUR GS (ANR-17-EURE-0003) within the Grenoble Partnership for Structural Biology. We thank Anne Chouquet for access to the SPR platform. Research reported in this manuscript was supported by the French National Research Agency (grants ANR-09-PIRI-0021 and ANR-16-CE11-0019). IBS acknowledges integration into the Interdisciplinary Research Institute of Grenoble (IRIG, CEA).

\section{References}

Arlaud, G.J., Sim, R.B., Duplaa, A.M., Colomb, M.G., 1979. Dif erential elution of Clq, Clr and Cls from human $\mathrm{Cl}$ bound to immune aggregates. $\mathrm{L}_{\cdot} \cdot$ in the rapid purification of $\mathrm{Cl}$ subcomponents. Mol. Immunol. 16, 445-450. ht ps:i'doi.org/10.1016/01615890(79)90069-5

Bally, I., Ancelet, S., Moriscot, C., Gonnet, F., Ma _wvani, A., Daniel, R., Schoehn, G., Arlaud, G.J., Thielens, N.M., 2013. Expression of $1^{\prime} \mathrm{oo}^{\prime}$ abinant human complement C1q allows identification of the $\mathrm{C} 1 \mathrm{r} / \mathrm{C} 1 \mathrm{~s}-\mathrm{bindin}$, te Proc. Natl. Acad. Sci. U.S.A. 110, 8650 8655. https://doi.org/10.1073/pnas. ' 3 C +894110

Bally, I., Dalonneau, F., Chouquet, A., Gröbı 'r, R., Amberger, A., Kapferer-Seebacher, I., Stoiber, H., Zschocke, J., Thielen. N.M., Rossi, V., Gaboriaud, C., 2019a. Two Different Missense C1S Mutations, Ass sc ، tea to Periodontal Ehlers-Danlos Syndrome, Lead to Identical Molecular Outcom `s. Ar snt Immunol 10, 2962.

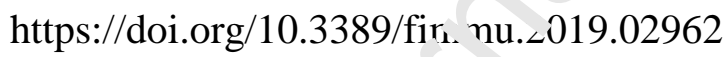

Bally, I., Inforzato, A., Dalonne. ', F., Stravalaci, M., Bottazzi, B., Gaboriaud, C., Thielens, N.M., 2019b. Interaction ot C1q With Pentraxin 3 and IgM Revisited: Mutational Studies With Recombinant $r_{l_{4}}{ }$ ariants. Front Immunol 10, 461. https://doi.org.'10. 338!/fimmu.2019.00461

Espericueta, V., Manughi’n-Peter, A.O., Bally, I., Thielens, N.M., Fraser, D.A., 2020. Recombinant C:? variants modulate macrophage responses but do not activate the classical complement pathway. Mol. Immunol. 117, 65-72. https://doi.org/10.1016/j.molimm.2019.10.008

Fouët, G., Bally, I., Signor, L., Häußermann, K., Thielens, N.M., Rossi, V., Gaboriaud, C., 2020. Headless C1q: a new molecular tool to decipher its collagen-like functions. FEBS J. https://doi.org/10.1111/febs.15543

Gaboriaud, C., Juanhuix, J., Gruez, A., Lacroix, M., Darnault, C., Pignol, D., Verger, D., Fontecilla-Camps, J.C., Arlaud, G.J., 2003. The crystal structure of the globular head of complement protein C1q provides a basis for its versatile recognition properties. J Biol Chem 278, 46974-46982. https://doi.org/10.1074/jbc.M307764200

Gaboriaud, C., Thielens, N.M., Gregory, L.A., Rossi, V., Fontecilla-Camps, J.C., Arlaud, G.J., 2004. Structure and activation of the $\mathrm{C} 1$ complex of complement: unraveling the puzzle. Trends Immunol 25, 368-373. https://doi.org/10.1016/j.it.2004.04.008 
Gadjeva, M.G., Rouseva, M.M., Zlatarova, A.S., Reid, K.B.M., Kishore, U., Kojouharova, M.S., 2008. Interaction of human C1q with IgG and IgM: revisited. Biochemistry 47, 1309313102. https://doi.org/10.1021/bi801131h

Koch, M., Veit, G., Stricker, S., Bhatt, P., Kutsch, S., Zhou, P., Reinders, E., Hahn, R.A., Song, R., Burgeson, R.E., Gerecke, D.R., Mundlos, S., Gordon, M.K., 2006. Expression of type XXIII collagen mRNA and protein. J. Biol. Chem. 281, 21546-21557. https://doi.org/10.1074/jbc.M604131200

Kouser, L., Madhukaran, S.P., Shastri, A., Saraon, A., Ferluga, J., Al-Mozaini, M., Kishore, U., 2015. Emerging and Novel Functions of Complement Protein C1q. Front Immunol 6, 317. https://doi.org/10.3389/fimmu.2015.00317

Kutyshenko, V.P., Mikoulinskaia, G.V., Chernyshov, S.V., Yegorov, A.Y., Prokhorov, D.A., Uversky, V.N., 2019. Effect of C-terminal His-tag and pur fication routine on the activity and structure of the metalloenzyme, l-alanyl-d-glutamate $\mathrm{p}_{\mathrm{L}}$ : dase of the bacteriophage T5. International Journal of Biological Macromolecules `24, 910-818. https://doi.org/10.1016/j.ijbiomac.2018.11.219

Lu, J.H., Teh, B.K., Wang, L. da, Wang, Y.N., Tan, Y.S., I ə. M. Z., Reid, K.B.M., 2008. The classical and regulatory functions of $\mathrm{C} 1 \mathrm{q}$ in immun. $\mathrm{v}$ and autoimmunity. Cell Mol Immunol 5, 9-21. https://doi.org/10.1038/cmi.2(108.?

Merle, N.S., Church, S.E., Fremeaux-Bacchi, V., Roumeı .ıa, L.T., 2015. Complement System Part I - Molecular Mechanisms of Activatir .. nnd Regulation. Front Immunol 6, 262. https://doi.org/10.3389/fimmu.2015.00262

Moreau, C., Bally, I., Chouquet, A., Bottaz7:- B., Thebrehiwet, B., Gaboriaud, C., Thielens, N., 2016. Structural and Functional $\mathrm{Cl}$. ${ }^{\mathrm{r}}$ rar cerization of a Single-Chain Form of the Recognition Domain of Complement 'rotein C1q. Front Immunol 7, 79. https://doi.org/10.3389/fimmu.2u'6.00079

Nayak, A., Ferluga, J., Tsolaki, A.G., K hnre, U., 2010. The non-classical functions of the classical complement pathw⿳v $1^{3}$ s sgnition subcomponent C1q. Immunol Lett 131, 139150. https://doi.org/10.10i /i.innlet.2010.03.012

Pflieger, D., Przybylski, C., Gon ret, ₹., Le Caer, J.-P., Lunardi, T., Arlaud, G.J., Daniel, R., 2010. Analysis of humaı Ciq by combined bottom-up and top-down mass spectrometry: detailed mapping of $n_{\mathrm{C}^{+}}^{+}$iranslational modifications and insights into the $\mathrm{C} 1 \mathrm{r} / \mathrm{C} 1 \mathrm{~s}$ binding sites. Mo. Cel Proteomics 9, 593-610. https://doi.org/10.1074/mcp.M900350MCP200

Reid, K.B., Edmondsor, I., 1984. Location of the binding site in subcomponent C1q for plasma fibronectin. Acta Pathol Microbiol Immunol Scand Suppl 284, 11-17.

Reid, K.B.M., 2018. Complement Component C1q: Historical Perspective of a Functionally Versatile, and Structurally Unusual, Serum Protein. Front Immunol 9, 764. https://doi.org/10.3389/fimmu.2018.00764

Ricklin, D., Hajishengallis, G., Yang, K., Lambris, J.D., 2010. Complement: a key system for immune surveillance and homeostasis. Nat Immunol 11, 785-797. https://doi.org/10.1038/ni.1923

Roumenina, L.T., Ruseva, M.M., Zlatarova, A., Ghai, R., Kolev, M., Olova, N., Gadjeva, M., Agrawal, A., Bottazzi, B., Mantovani, A., Reid, K.B.M., Kishore, U., Kojouharova, M.S., 2006. Interaction of $\mathrm{C} 1 \mathrm{q}$ with $\mathrm{IgG} 1, \mathrm{C}$-reactive protein and pentraxin 3: mutational studies using recombinant globular head modules of human $\mathrm{C} 1 \mathrm{q} \mathrm{A}, \mathrm{B}$, and $\mathrm{C}$ chains. Biochemistry 45, 4093-4104. https://doi.org/10.1021/bi052646f 
Thielens, N.M., Tedesco, F., Bohlson, S.S., Gaboriaud, C., Tenner, A.J., 2017. C1q: A fresh look upon an old molecule. Mol. Immunol. 89, 73-83. https://doi.org/10.1016/j.molimm.2017.05.025

Zlatarova, A.S., Rouseva, M., Roumenina, L.T., Gadjeva, M., Kolev, M., Dobrev, I., Olova, N., Ghai, R., Jensenius, J.C., Reid, K.B.M., Kishore, U., Kojouharova, M.S., 2006. Existence of different but overlapping IgG- and IgM-binding sites on the globular domain of human C1q. Biochemistry 45, 9979-9988. https://doi.org/10.1021/bi060539v 


\section{Figure Legends}

Figure 1. Schematic representation of C1q chains pattern and SDS-PAGE analysis of the C1q variants. (A) C1q comprises three polypeptide chains (A, B and C) each containing an $\mathrm{N}$-terminal collagen-like sequence and a C-terminal gC1q module. A particular inter-chain disulfide pattern (A-B and C-C) results in a basic subunit comprised of two heterotrimeric collagen-like stalks prolonged by globular domains. Three subunits associate non-covalently to yield the full-length protein with a typical shape of a bouquet of six flowers. (B, C) Four $\mu \mathrm{g}$ of each variant were analyzed by SDS-PAGE and Coomassie blue staining, under non-reducing (B) and reducing (C) conditions, allowing visualization of the A-B and C-C dimers, and us the three individual chains, respectively.

Figure 2. Kinetic analyses of the interaction of $\operatorname{IgM} a t_{1}=\mathrm{Clr}_{2}-\mathrm{Cls}_{2}$ tetramer with immobilized C1q variants. Sixty $\mu 1$ of $\operatorname{IgM}$ or of the $C 1_{1_{-}}-1 \mathrm{~s}_{2}$ tetramer at the indicated concentrations were injected over rC1q_C-FLAG 1?,,00 RU) (A, F),) rC1q_A-FLAG (12,900 RU) (B, G), rC1q_B-FLAG (11,800 RU) (C, 'T), 'C1q_FLAG-C (13,700 RU) (D, I) and rC1q_C-Myc (13,400 RU) (E, J) in 50 mM ? is- $\mathrm{HCl}, 150 \mathrm{mM} \mathrm{NaCl}, 2 \mathrm{mM} \mathrm{CaCl} 2,0.05 \%$ surfactant P20, pH 7.4 at a flow rate of $\angle \mathrm{i}$ ul/min. The binding signals shown were obtained by subtracting the signal over the BSA $r(f)$ re ${ }_{4}$ ce surface and further subtraction of buffer blanks. Fits are shown as black lines and 、 ere ubtained by global fitting of the data using a 1:1 Langmuir binding model. Eaci. k1. atic analysis shown is representative of two to four experiments performed on rap. wite sensor chips.

Figure 3. IgM-depend ` . complement activation by the C1q variants. C1q-depleted human serum (1:25 dilution) was reconstituted with the recombinant C1q variants $(4 \mu \mathrm{g} / \mathrm{ml})$ and added to microwells coated with $2 \mu \mathrm{g} / \mathrm{ml}$ IgM. The resulting C1-cleaving activity was measured by a C4b deposition assay as described under Material and Methods. Deposited C4b was detected with an anti-human polyclonal antibody, and results are expressed as absorbance at $450 \mathrm{~nm}$ $\left(\mathrm{OD}_{450}\right)$, (means \pm SEM of two independent experiments each performed in duplicate). Normal human serum (NHS, 1:25 dilution) is shown as a positive control. Ctrl: signal obtained without IgM coated. 
Figure 4. Three-dimensional model of C1q highlighting the location of the affinity tags and the IgM and $\mathrm{C1}_{2} \mathbf{r}_{2}-\mathrm{Cls}_{2}$ tetramer binding sites. The model was assembled as described previously

(Gaboriaud et al., 2004, 2003; Pflieger et al., 2010). The C1q chains are colored dark blue (A), green (B), and cyan $(\mathrm{C})$. Red arrows indicate the location of the $\mathrm{N}$-terminal and $\mathrm{C}$-terminal tags. The positions of the side chains of the three lysine residues involved in the interaction with $\mathrm{C}_{2} \mathrm{r}_{2}-\mathrm{C}_{1} \mathrm{~s}_{2}$ and of the two arginine and the tyrosine residues important for IgM binding are shown. 
TABLE 1. Kinetic and dissociation constants for binding of $\mathrm{IgM}$ and the $\mathrm{C} 1 \mathrm{r}_{2}-\mathrm{C} 1 \mathrm{~s}_{2}$ tetramer to immobilized C1q variants

\begin{tabular}{|c|c|c|c|c|c|c|}
\hline \multirow[t]{2}{*}{ C1q ligand } & \multirow[t]{2}{*}{ Constants } & \multicolumn{4}{|c|}{ Immobilized C1q variants } & \multirow[b]{2}{*}{ N-ter-CFlag } \\
\hline & & CFlag-Cter & AFlag-Cter & BFlag-CTer & Cmyc-CTer & \\
\hline \multirow[t]{3}{*}{$\lg M$} & $k_{\mathrm{a}}\left(\mathrm{M}^{-1} \mathrm{~s}^{-1}\right)$ & $\begin{array}{l}1.34 \pm 0.05 \times 10^{6} \\
\left(9.19 \pm 2.08 \times 10^{6}\right)\end{array}$ & $1.78 \pm 0.02 \times 10^{6}$ & $1.65 \pm 0.01 \times 10^{6}$ & $1.20 \pm 0.02 \times 10^{6}$ & $1.12 \pm 0.03 \times 10^{6}$ \\
\hline & $k_{d}\left(\mathrm{~s}^{-1}\right)$ & $\begin{array}{l}1.84 \pm 0.11 \times 10^{-3} \\
\left(1.54 \pm 0.19 \times 10^{-3}\right)\end{array}$ & $1.75 \pm 0.01 \times 10^{-3}$ & $1.83 \pm 0.01 \times 10^{-3}$ & $1.85 \pm 0.04 \times 10^{-3}$ & $1.82 \pm 0.02 \times 10^{-3}$ \\
\hline & $K_{D}(\mathrm{M})$ & $\begin{array}{l}1.38 \pm 0.13 \times 10^{-9} \\
\left(1.92 \pm 0.68 \times 10^{-9}\right)\end{array}$ & $9.84 \pm 0.07 \times 10^{-10}$ & $1.11 \pm 0.01 \times 10$ & $1.54 \pm 0.07 \times 10^{-9}$ & $1.63 \pm 0.06 \times 10^{-9}$ \\
\hline \multirow[t]{3}{*}{$\mathrm{C} 1 \mathrm{r}_{2}-\mathrm{C} 1 \mathrm{~s}_{2}$} & $k_{a}\left(M^{-1} \mathrm{~s}^{-1}\right)$ & $\begin{array}{l}8.07 \pm 0.99 \times 10^{5} \\
\left(4.35 \pm 0.15 \times 10^{5}\right)\end{array}$ & $5.55 \pm 0.05 \times 10^{5}$ & $6.11 \pm 0.15 \times 1 \iota^{5}$ & 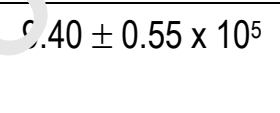 & $7.41 \pm 0.57 \times 10^{5}$ \\
\hline & $k_{d}\left(\mathrm{~s}^{-1}\right)$ & $\begin{array}{l}3.66 \pm 0.12 \times 10^{-3} \\
\left(2.88 \pm 0.19 \times 10^{-3}\right)\end{array}$ & $2.90 \pm 0.09 \times 10^{-3}$ & $3.20 \pm 0 . .^{?} \times 10^{-3}$ & $3.44 \pm 0.05 \times 10^{-3}$ & $3.50 \pm 0.22 \times 10^{-3}$ \\
\hline & $K_{D}(M)$ & $\begin{array}{l}4.58 \pm 0.44 \times 10^{-9} \\
\left(6.36 \pm 0.42 \times 10^{-9}\right)\end{array}$ & $5.22 \pm 0.12 \times 10^{-9}$ & $5.2 ; \pm 0.27 \times 10^{-9}$ & $3.67 \pm 0.21 \times 10^{-9}$ & $4.72 \pm 0.06 \times 10^{-9}$ \\
\hline
\end{tabular}

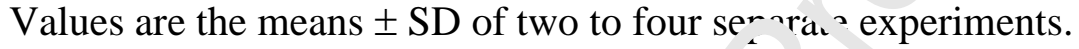

The values in parentheses for the CFlag-C er v ariant correspond to previously published values (Bally et al., 2019b) 
- Recombinant C1q can be produced with a FLAG or Myc tag fused to A, B or C chain

- A C-terminal His-tag fused the $\mathrm{C}$ chain impedes recombinant $\mathrm{C} 1 \mathrm{q}$ production

- The FLAg- or Myc-tagged C1q variants interact with IgM and the $\mathrm{C} 1 \mathrm{r} / \mathrm{C} 1$ s proteases

- The newly produced C1q variants trigger IgM-mediated serum complement activation

- The tag location is not a limiting factor for functional recombinant $\mathrm{C} 1 \mathrm{q}$ production 
A

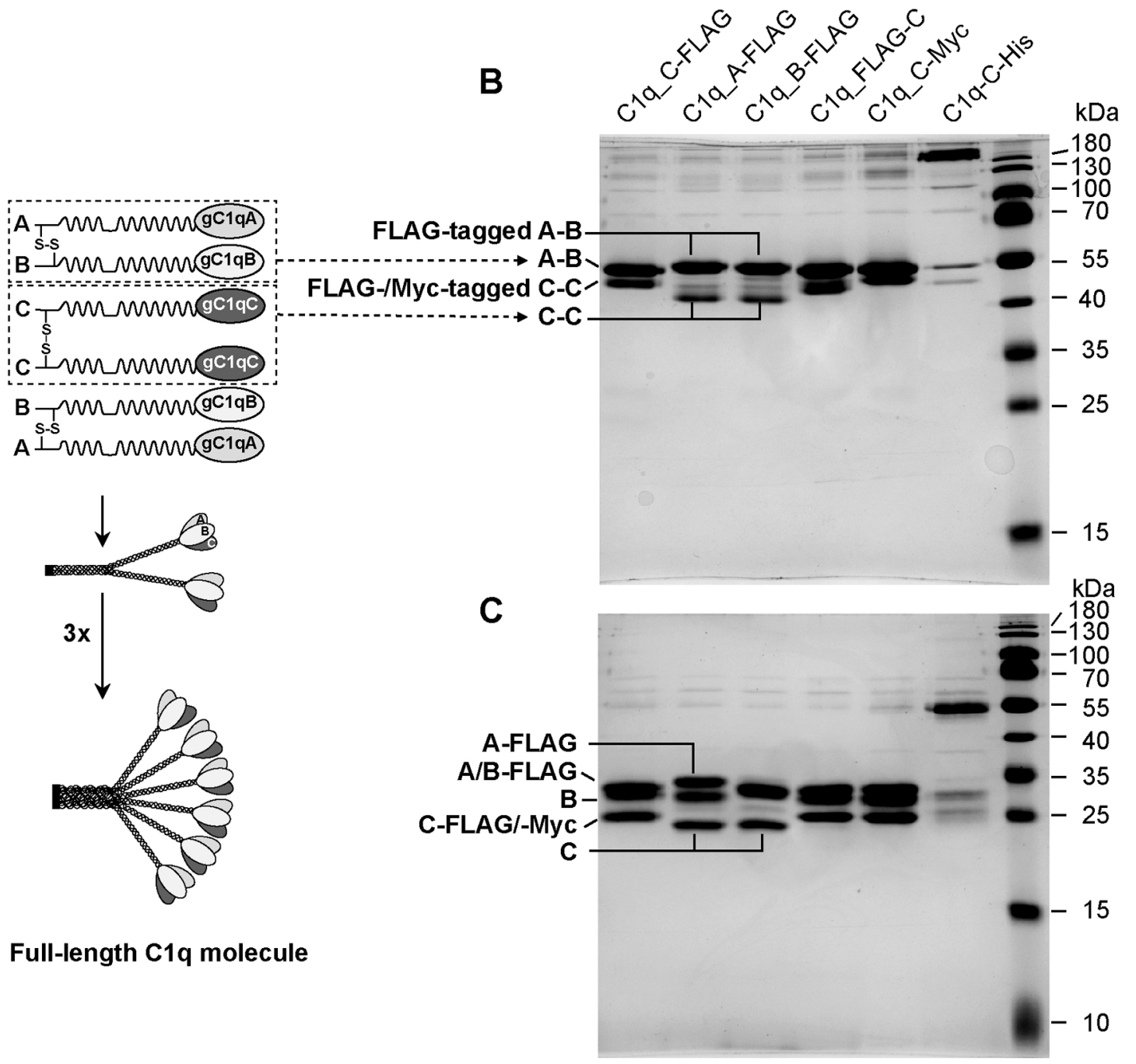

Figure 1 
A

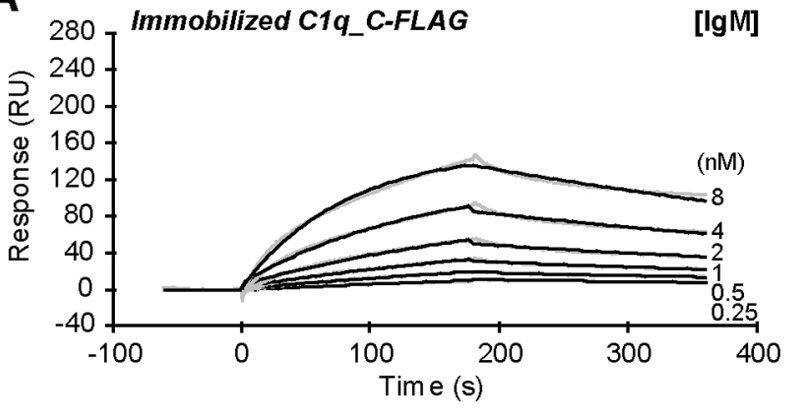

B

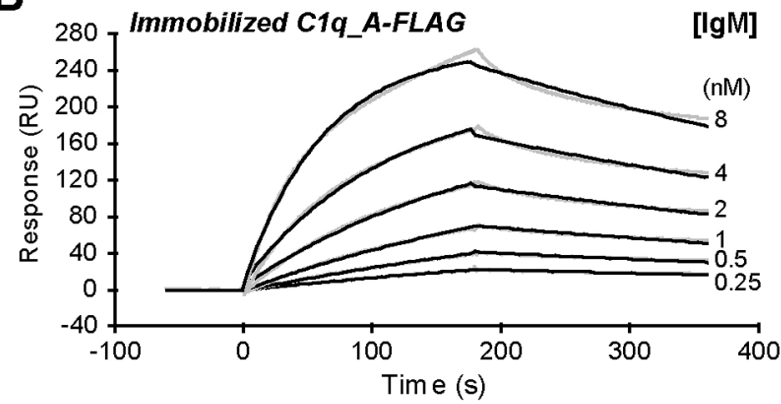

C

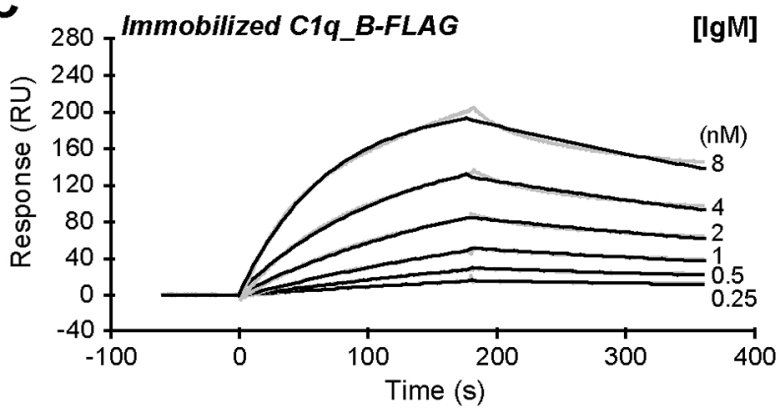

D

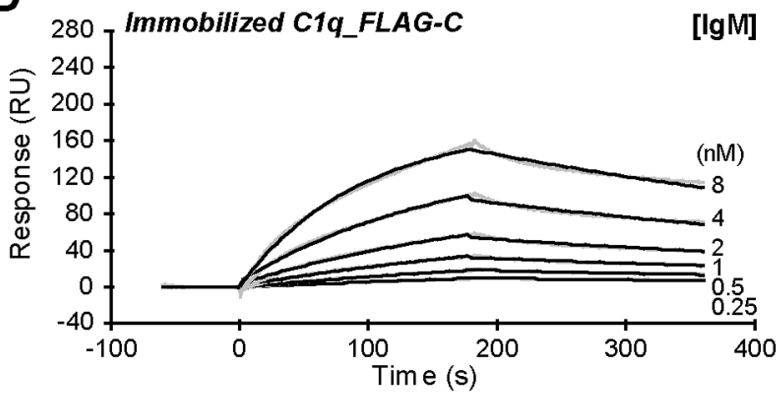

E

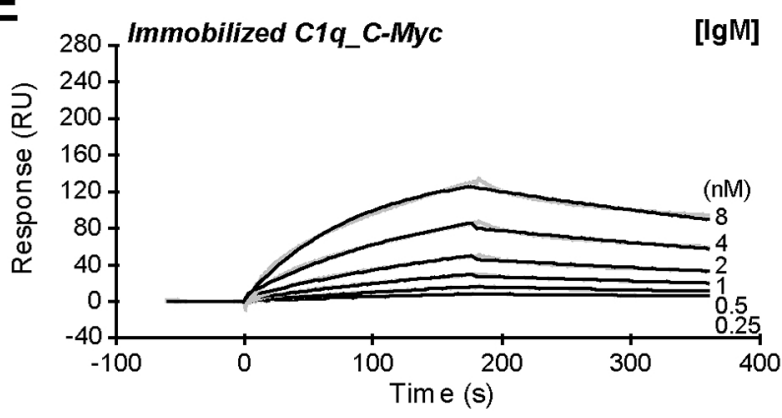

F

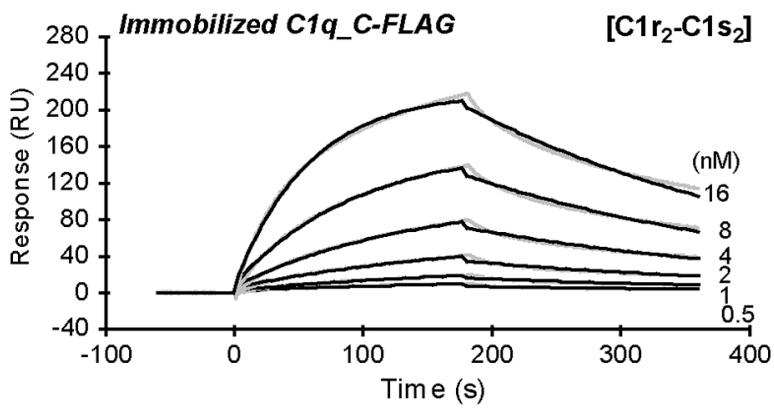

G

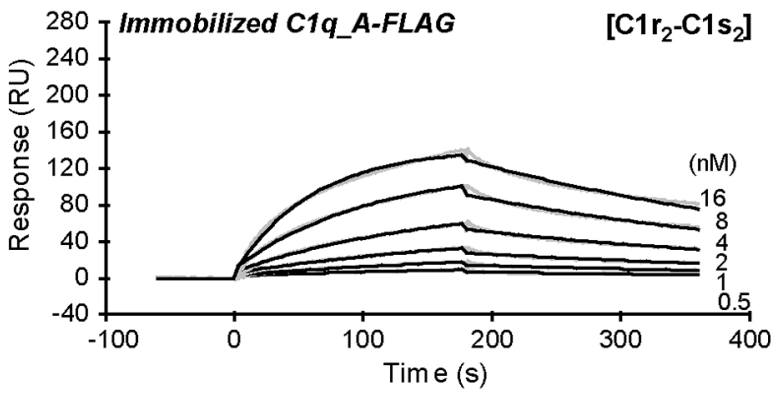

H
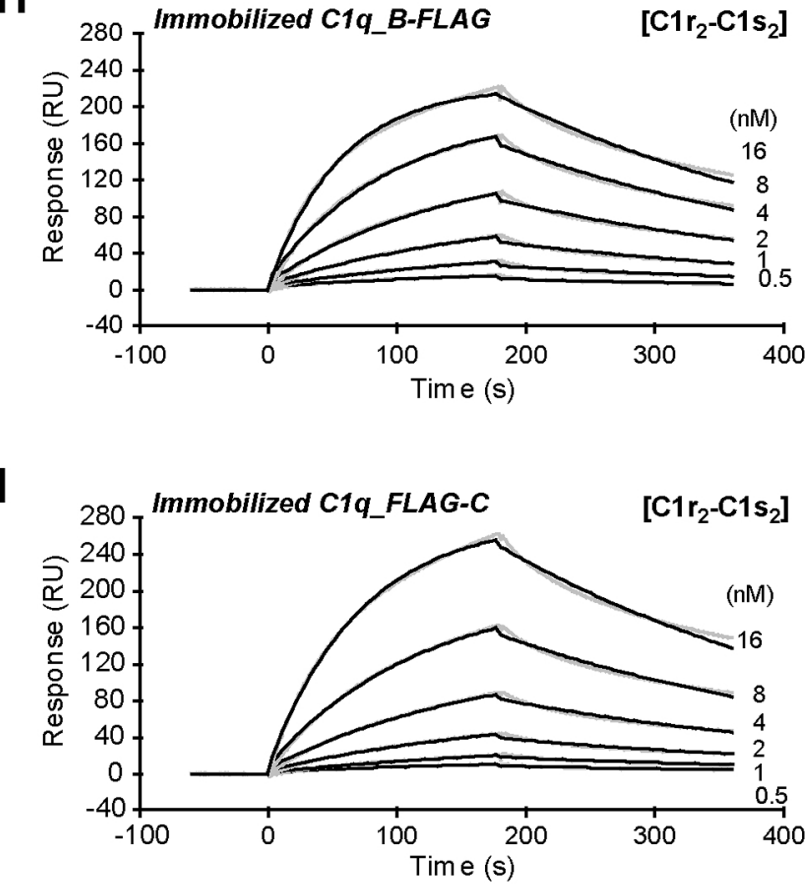

J

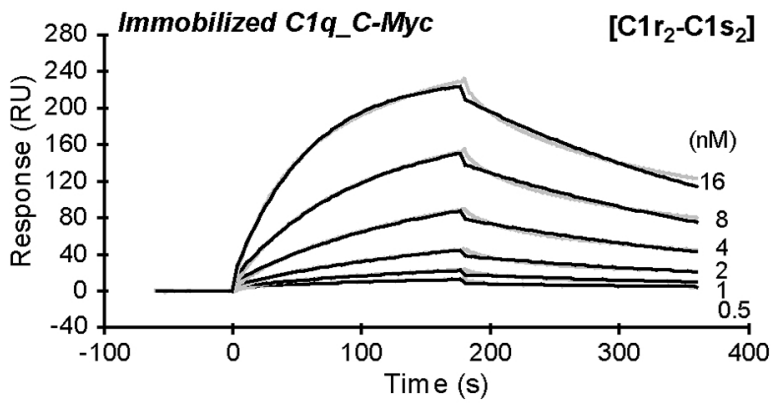




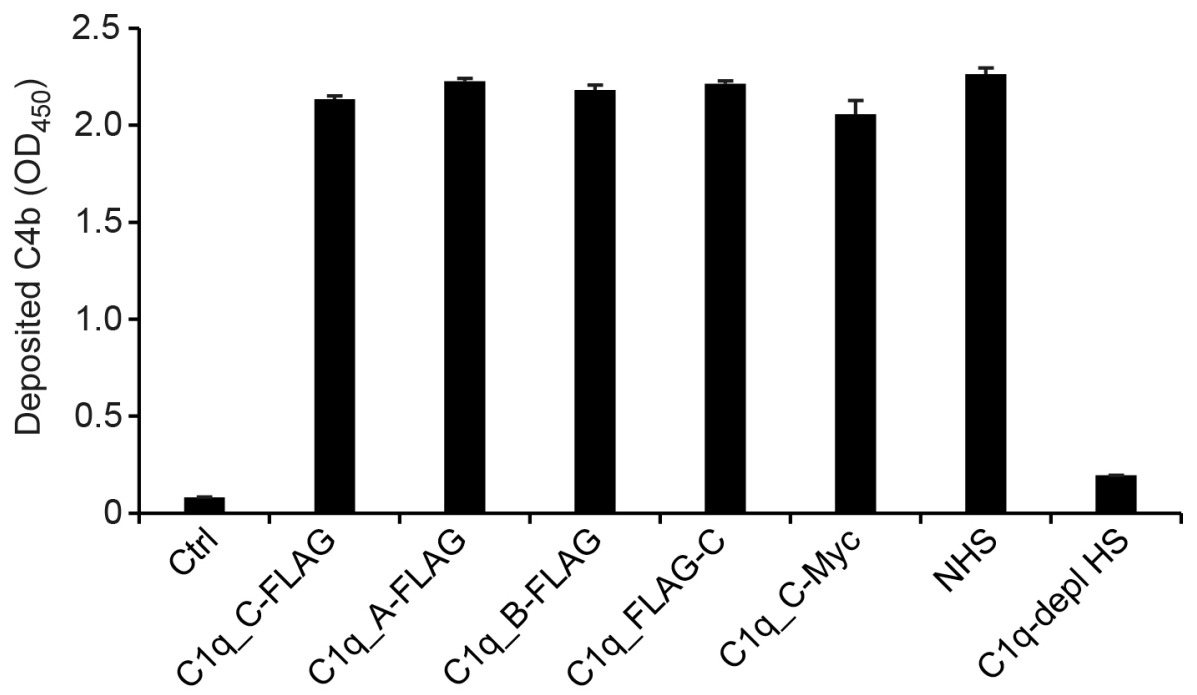

Figure 3 


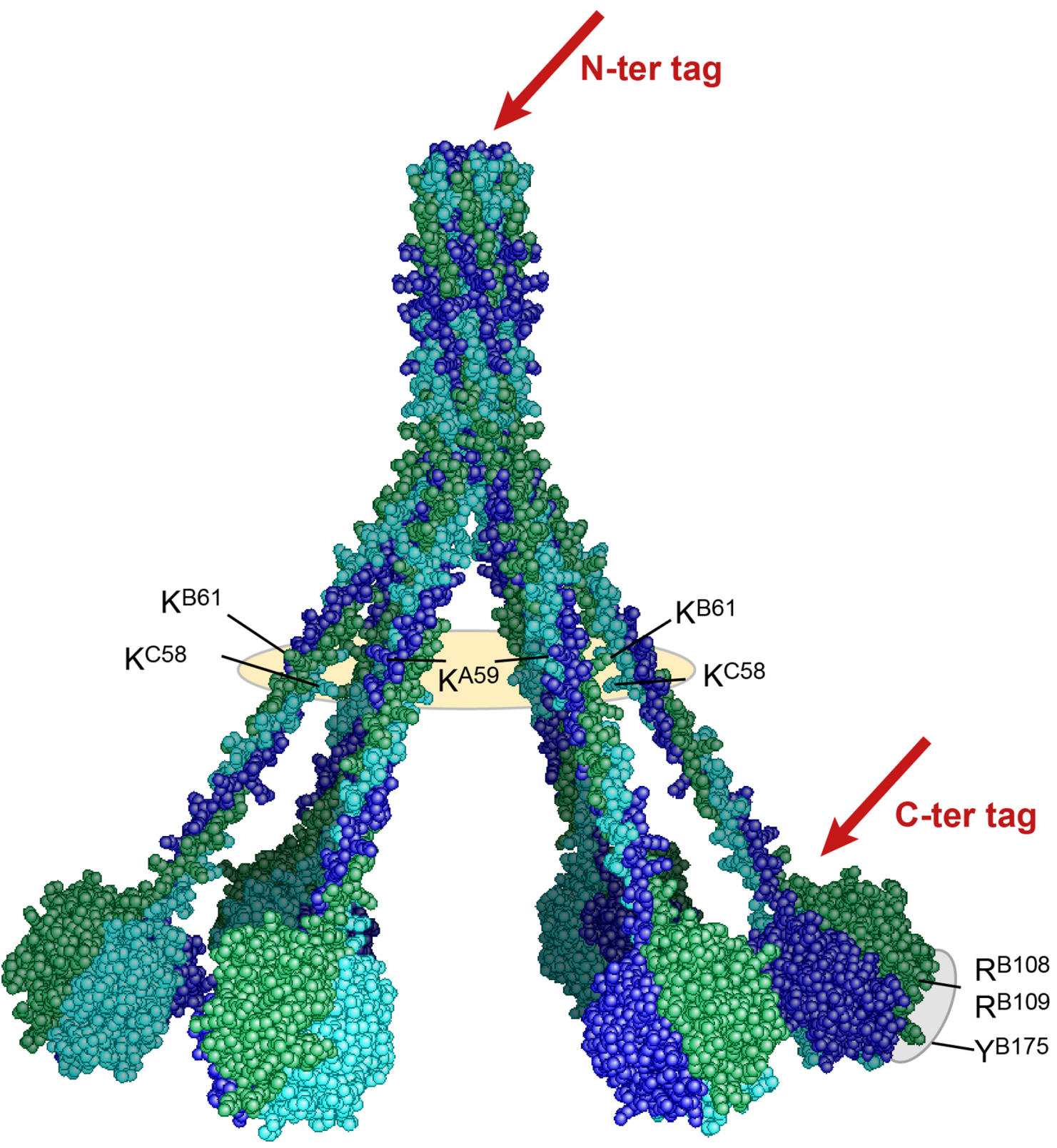

Figure 4 